\title{
Impact of body mass index on clinicopathological outcomes in patients with renal cell carcinoma without anorexia-cachexia syndrome
}

\author{
DAISUKE WATANABE, AKIO HORIGUCHI, SHINSUKE TASAKI, KENJI KURODA, \\ AKINORI SATO, JUNICHI ASAKUMA, KEIICHI ITO and TOMOHIKO ASANO \\ Department of Urology, National Defense Medical College, Tokorozawa 359-8513, Japan
}

Received February 23, 2017; Accepted July 4, 2017

DOI: $10.3892 / \mathrm{mco} .2017 .1473$

\begin{abstract}
Although obesity defined by a high body mass index (BMI) is generally associated with increased risk of renal cell carcinoma ( $\mathrm{RCC}$ ), low BMI has paradoxically been associated with increased tumor aggressiveness and poor prognosis. As anorexia-cachexia syndrome (ACS) is associated with decreased BMI and is frequently observed in patients with advanced RCC, the present study investigated the association of BMI with tumor aggressiveness and prognosis in RCC in relation to ACS. The association of BMI with clinicopathological parameters was analyzed in 503 consecutive patients who underwent surgery for RCC. Kaplan-Meier curves and rates of overall survival (OS) stratified by BMI were also compared in relation to the presence or absence of ACS, defined as the presence of anorexia or malaise, and/or weight loss and/or hypoalbuminemia. Low BMI was significantly associated with high-grade tumors $(\mathrm{P}=0.0027)$ and the presence of distant metastasis $(\mathrm{P}=0.0025)$, and patients with a lower BMI had significantly shorter OS than those with a higher BMI $(\mathrm{P}=0.0441)$. Patients with ACS had a significantly lower BMI (mean, $21.5 \mathrm{~kg} / \mathrm{m}^{2}$ ) than those without ACS (mean, $\left.23.5 \mathrm{~kg} / \mathrm{m}^{2} ; \mathrm{P}<0.0001\right)$ and had significantly shorter OS than those without ACS $(\mathrm{P}<0.0001)$. On multivariate analysis, ACS was an independent predictor of short OS $[\mathrm{P}=0.0089$; hazard ratio (HR), 2.21; 95\% confidence interval (CI), 1.22-3.92] and short cancer-specific survival $(\mathrm{P}=0.0308$; $\mathrm{HR}$, 2.03; 95\% CI, 1.07-3.78); however, BMI was not $(\mathrm{P}=0.5440$ and $\mathrm{P}=0.6804$, respectively). In the 413 patients without ACS at initial presentation, BMI was not associated with any clinicopathological parameters or OS (log-rank, $\mathrm{P}=0.4591$ ). $\mathrm{BMI}$ itself was not a predictor of survival in patients without
\end{abstract}

Correspondence to: Dr Daisuke Watanabe, Department of Urology, National Defense Medical College, 3-2 Namiki, Tokorozawa 359-8513, Japan

E-mail: beyan1118@gmail.com

Key words: anorexia, cachexia, body mass index, obesity, renal cell carcinoma, overall survival
ACS, and the association between low BMI and increased tumor aggressiveness and poor prognosis could be due to ACS.

\section{Introduction}

The prevalence of obesity and being overweight, defined by a high body mass index (BMI), have been increasing regardless of sex, age and whether people live in developed or developing countries (1). Health problems related to being obese have become an issue worldwide. The complications of obesity, such as cardiovascular disorder, diabetes and other metabolic diseases, frequently arise at a lower BMI in Asian nations than they do in Europe and North America (2); therefore, more attention is required for this in Asia. Obesity has been recognized as a notable risk factor for various malignant tumors, among which colon and rectal cancer, endometrial cancer and postmenopausal breast cancer are well known (3). Obesity is also a well-known risk factor for the development of renal cell carcinoma (RCC) (3-5).

The majority of studies investigating the association between obesity and survival in prostate cancer and colorectal cancer have suggested poorer rather than better survival for obese patients (6,7). Regarding RCC, however, an inverse relationship between BMI and prognosis has been reported, not only in the United States and European countries (8-10), but also in Asia $(11,12)$. These studies demonstrated that overweight and obese patients were less likely to present with aggressive forms of tumors or have poor survival $(9,13)$.

RCC may present with a wide variety of paraneoplastic symptoms, and anorexia-cachexia syndrome (ACS) is one of the most common $(14,15)$. ACS is a complex metabolic disorder, involving loss of adipose tissue due to lipolysis, loss of skeletal muscle mass, elevation of resting energy expenditure, anorexia and reduction in food intake (16). As a result, patients with ACS lose weight and tend to have a low BMI. As patients with ACS have markedly shorter survival in RCC $(14,15)$, we postulated that the association of low BMI with tumor aggressiveness and poor prognosis may be due to ACS. The purpose of the present study was to evaluate the association of BMI with tumor aggressiveness and prognosis in RCC while taking ACS into account. 


\section{Patients and methods}

Ethics statement. All procedures performed in studies involving human participants were in accordance with the ethical standards of the Ethics Committee of National Defense Medical College (Tokorozawa, Japan) and with the 1964 Helsinki declaration and its later amendments. Informed consent was obtained from all individual participants included in the study.

Patients. A total of 503 consecutive patients (374 males and 129 females; mean age at surgery, 62.5 years) who underwent radical or partial nephrectomy for RCC at the National Defense Medical College Hospital between November 1983 and January 2014 were retrospectively reviewed. All tumor tissues were evaluated for pathological staging and histological grading according to the TNM classification (17), and the cases before 2010 were re-described according to the TNM classification by the Pathology Department of our institution. Age, sex, Eastern Cooperative Oncology Group Performance Status (ECOG-PS) scale (18), the presence or absence of ACS at initial presentation, BMI, regional lymph node (LN) involvement, presence of distant metastasis and various pathological parameters were assessed. ACS at the initial presentation was defined as the presence of anorexia or malaise, and/or weight loss and/or hypoalbuminemia $(14,15)$. Weight loss was defined as unintentional weight decrease within several months, regardless of the amount. Anorexia was defined as abnormal loss of the appetite for food, and malaise was defined as fatigue or general body discomfort. Hypoalbuminemia was defined as a preoperative serum albumin level $<3.8 \mathrm{mg} / \mathrm{dl}$. BMI was estimated at the time of surgery by dividing the patient's weight in $\mathrm{kg}$ by the square of the patient's height in m. Patients were grouped into the following four categories based on the World Health Organization (WHO) classification for Asian populations: Underweight $\left(\mathrm{BMI}<18.5 \mathrm{~kg} / \mathrm{m}^{2}\right)$; normal weight $\left(\mathrm{BMI}=18.5-23 \mathrm{~kg} / \mathrm{m}^{2}\right)$; overweight $\left(23 \leq \mathrm{BMI}<25 \mathrm{~kg} / \mathrm{m}^{2}\right)$, obese $\left(B M I \geq 25 \mathrm{~kg} / \mathrm{m}^{2}\right)$ (19).

Statistical analysis. Data were presented as the mean \pm standard deviation. The Mann-Whitney U test was used for comparisons of continuous variables among clinical and pathological parameter groups. The Kaplan-Meier method with the log-rank test was used to compare overall survival (OS) rates between RCC patient groups. Univariate and multivariate Cox proportional hazard models were used to identify which clinical and pathological parameters, including BMI and ACS, independently predicted OS and cancer-specific survival (CSS). All statistical analyses were performed using $\mathrm{JMP}^{\circledR} 10$ (SAS Institute, Inc., Cary, NC, USA). $\mathrm{P}<0.05$ was considered to indicate a statistically significant difference.

\section{Results}

Patient characteristics. The patient characteristics and pathological parameters are listed in Table I. The present cohort comprised 374 males (74.4\%) and 129 females (25.6\%), and the mean age at surgery was 62.5 years (range, 29-89 years). Mean follow-up duration from the date of surgery to the last recorded follow-up was 59.3 months (range, 0.1-248.4 months), there were 65 mortalities as a result of cancer, and there were 11 mortalities due to other causes. Anorexia or malaise
Table I. Patient characteristics.

\begin{tabular}{|c|c|}
\hline Characteristic & $\mathrm{n}(\%)$ \\
\hline Total & 503 \\
\hline \multicolumn{2}{|l|}{ Sex } \\
\hline Male & $374(74.4)$ \\
\hline Female & $129(25.6)$ \\
\hline \multicolumn{2}{|c|}{ Eastern Cooperative Oncology Group PS } \\
\hline PS0-1 & $482(95.8)$ \\
\hline PS2-4 & $21(4.2)$ \\
\hline \multicolumn{2}{|l|}{ Anorexia or malaise } \\
\hline Negative & $466(92.6)$ \\
\hline Positive & $37(7.4)$ \\
\hline \multicolumn{2}{|l|}{ Weight loss } \\
\hline Negative & $472(93.8)$ \\
\hline Positive & $31(6.2)$ \\
\hline \multicolumn{2}{|l|}{ Hypoalbuminemia } \\
\hline Negative & $432(85.9)$ \\
\hline Positive & $71(14.1)$ \\
\hline \multicolumn{2}{|l|}{ Anorexia-cachexia syndrome } \\
\hline Negative & $413(82.1)$ \\
\hline Positive & $90(17.9)$ \\
\hline \multicolumn{2}{|l|}{ BMI, kg/m² } \\
\hline Underweight $(<18.5)$ & $36(7.2)$ \\
\hline Normal $(18.5 \leq \mathrm{BMI}<23)$ & $218(43.3)$ \\
\hline Overweight $(23 \leq \mathrm{BMI}<25)$ & $130(25.8)$ \\
\hline Obese $(\mathrm{BMI} \geq 25)$ & $119(23.7)$ \\
\hline \multicolumn{2}{|l|}{ Histological type } \\
\hline Clear cell & $424(84.3)$ \\
\hline Other & $79(15.7)$ \\
\hline \multicolumn{2}{|l|}{ Grade } \\
\hline Low (G1-2) & $328(65.2)$ \\
\hline High (G3) & $175(34.8)$ \\
\hline \multicolumn{2}{|l|}{ Pathological T stage } \\
\hline pT1-2 & $398(79.1)$ \\
\hline pT3-4 & $105(20.9)$ \\
\hline \multicolumn{2}{|l|}{ Venous invasion } \\
\hline Negative & $288(57.3)$ \\
\hline Positive & $215(42.7)$ \\
\hline \multicolumn{2}{|l|}{ Growth pattern } \\
\hline Expansive & $334(66.4)$ \\
\hline Infiltrative & $169(33.6)$ \\
\hline \multicolumn{2}{|c|}{ Regional lymph node involvement } \\
\hline Negative & $488(97.0)$ \\
\hline Positive & $15(3.0)$ \\
\hline \multicolumn{2}{|l|}{ Distant metastasis } \\
\hline Negative & $446(88.7)$ \\
\hline Positive & $57(11.3)$ \\
\hline
\end{tabular}

BMI, body mass index; PS, performance status.

(37 patients, $7.4 \%$ ), weight loss (31 patients, 6.2\%) and hypoalbuminemia (71 patients, $14.1 \%$ ) were observed at initial 
Table II. Association between BMI and clinicopathological parameters in all patients and in patients without ACS.

\begin{tabular}{|c|c|c|c|c|c|c|}
\hline \multirow[b]{2}{*}{ Parameter } & \multicolumn{3}{|c|}{ All patients } & \multicolumn{3}{|c|}{ Patients without ACS } \\
\hline & $\mathrm{n}$ & BMI, $\mathrm{kg} / \mathrm{m}^{2}$ & P-value & $\mathrm{n}$ & $\mathrm{BMI}, \mathrm{kg} / \mathrm{m}^{2}$ & P-value \\
\hline Grade & & & 0.0027 & & & 0.0616 \\
\hline G1-2 & 328 & $23.4 \pm 3.57$ & & 301 & $23.6 \pm 3.58$ & \\
\hline G3 & 175 & $22.5 \pm 3.39$ & & 112 & $23 \pm 3.45$ & \\
\hline Pathological T stage & & & 0.0789 & & & 0.5415 \\
\hline pT1-2 & 398 & $23.3 \pm 3.64$ & & 352 & $23.5 \pm 3.65$ & \\
\hline pT3-4 & 105 & $22.4 \pm 3.02$ & & 61 & $23.0 \pm 2.86$ & \\
\hline Regional lymph node involvement & & & 0.2167 & & & 0.7041 \\
\hline Negative & 488 & $23.1 \pm 3.52$ & & 405 & $23.5 \pm 3.56$ & \\
\hline Positive & 15 & $21.6 \pm 3.90$ & & 8 & $23.4 \pm 3.35$ & \\
\hline Distant metastasis & & & 0.0025 & & & 0.0807 \\
\hline Negative & 446 & $23.3 \pm 3.59$ & & 386 & $23.5 \pm 3.59$ & \\
\hline Positive & 57 & $21.9 \pm 2.78$ & & 27 & $22.4 \pm 2.81$ & \\
\hline Venous invasion & & & 0.7709 & & & 0.2139 \\
\hline Negative & 288 & $23.2 \pm 3.85$ & & 261 & $23.5 \pm 3.88$ & \\
\hline Positive & 215 & $22.9 \pm 3.06$ & & 152 & $23.5 \pm 2.92$ & \\
\hline Growth pattern & & & 0.0453 & & & 0.6627 \\
\hline Expansive & 334 & $23.4 \pm 3.61$ & & 299 & $23.5 \pm 3.62$ & \\
\hline Infiltrative & 169 & $22.6 \pm 3.34$ & & 114 & $23.5 \pm 3.37$ & \\
\hline $\mathrm{ACS}$ & & & $<0.0001$ & & & - \\
\hline Negative & 413 & $23.5 \pm 3.55$ & & - & - & \\
\hline Positive & 90 & $21.5 \pm 2.98$ & & - & - & \\
\hline
\end{tabular}

Data are presented as the mean \pm standard deviation. ACS, anorexia-cachexia syndrome; BMI, body mass index.

A

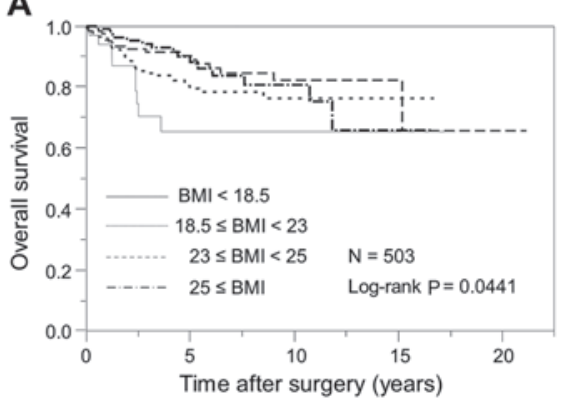

B

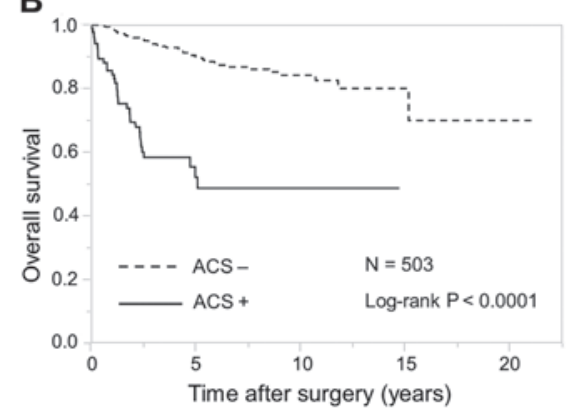

C

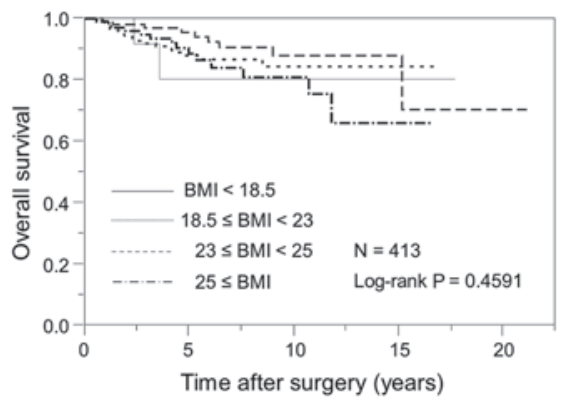

Figure 1. Kaplan-Meier curves for overall survival of patients with renal cell carcinoma. (A) Overall survival in all patients stratified by BMI categories. (B) Overall survival in all patients with or without ACS. (C) Overall survival in patients without ACS stratified by BMI categories. BMI, body mass index; ACS, anorexia-cachexia syndrome.

presentation, and 90 patients $(17.9 \%)$ were considered to have ACS according to our definition. Of the 503 patients in this cohort, $424(84.3 \%)$ had clear cell type tumors, 175 (34.8\%) had high-grade tumors, $398(79.1 \%)$ had pathological T stage 1-2 tumors, 15 (3.0\%) had LN metastasis and 57 (11.3\%) had distant metastasis.

Association of BMI with pathological parameters and clinical outcome. Lower BMI has been reported to be associated with aggressive forms of RCC and with shorter survival (9-13). The association between BMI and clinicopathological parameters in our cohort is presented in Table II. In accordance with the results of previous studies, BMI was significantly lower in patients with high-grade tumors $(\mathrm{P}=0.0027)$, patients with distant metastasis at the time of surgery $(\mathrm{P}=0.0025)$ and patients having tumors with an infiltrative pattern $(\mathrm{P}=0.0453)$. Kaplan-Meier curves for OS stratified according to WHO BMI categories for Asian populations are demonstrated in Fig. 1A. Patients with a lower BMI had significantly shorter OS than those with a higher BMI (log-rank, $\mathrm{P}=0.0441)$. 


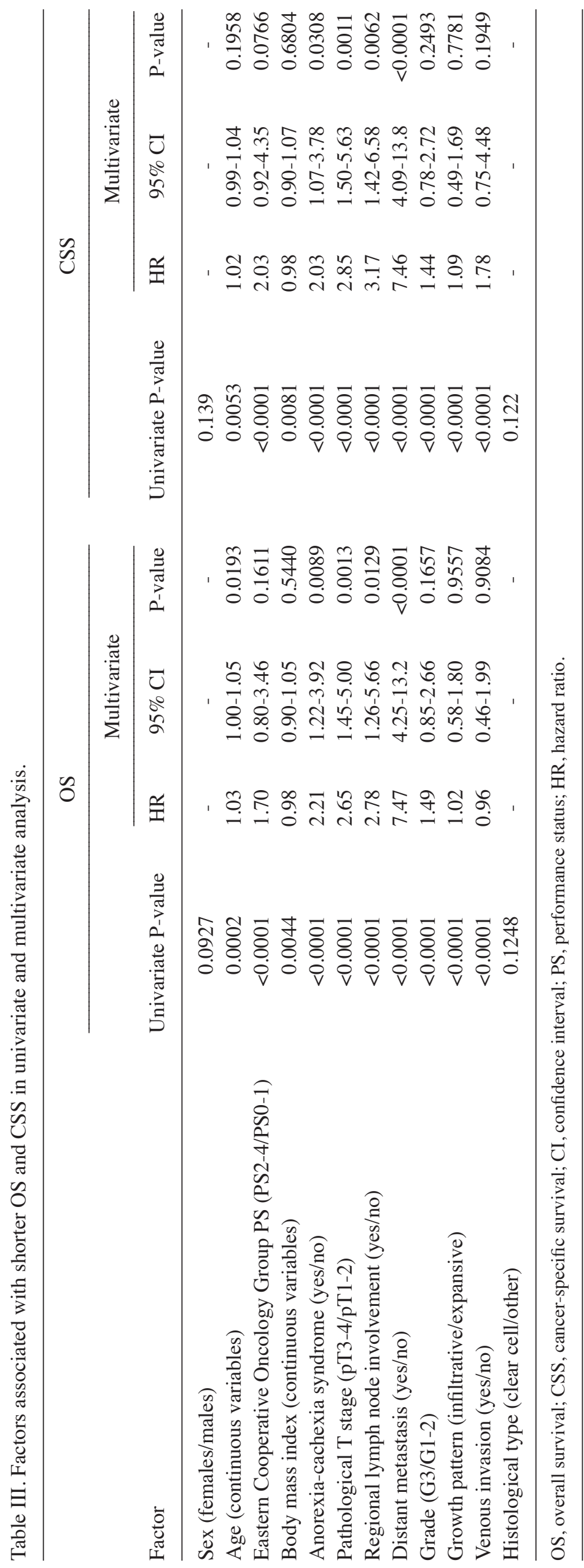


Table IV. Constituent factors of anorexia-cachexia syndrome associated with shorter OS and CSS in univariate and multivariate analysis.

\begin{tabular}{|c|c|c|c|c|c|c|c|c|}
\hline \multirow[b]{3}{*}{ Factor } & \multicolumn{4}{|c|}{ OS } & \multicolumn{4}{|c|}{ CSS } \\
\hline & \multicolumn{2}{|c|}{ Univariate } & \multicolumn{2}{|c|}{ Multivariate } & \multicolumn{2}{|c|}{ Univariate } & \multicolumn{2}{|c|}{ Multivariate } \\
\hline & HR (95\% CI) & P-value & $\mathrm{HR}(95 \% \mathrm{CI})$ & P-value & $\mathrm{HR}(95 \% \mathrm{CI})$ & P-value & $\mathrm{HR}(95 \% \mathrm{CI})$ & P-value \\
\hline Weight loss & $11.8(6.99-19.5)$ & $<0.0001$ & $8.34(2.38-28.9)$ & 0.0004 & $12.5(7.13-21.2)$ & $<0.0001$ & $8.26(2.21-30.5)$ & 0.0009 \\
\hline Hypoalbuminemia & $3.86(2.29-6.31)$ & $<0.0001$ & $1.53(0.78-2.90)$ & 0.2111 & $4.11(2.36-6.92)$ & $<0.0001$ & $1.60(0.79-3.16)$ & 0.1876 \\
\hline Anorexia or malaise & $8.37(4.97-13.7)$ & $<0.0001$ & $1.12(0.30-4.04)$ & 0.8721 & $8.92(5.12-15.0)$ & $<0.0001$ & $1.16(0.29-4.50)$ & 0.8366 \\
\hline
\end{tabular}

OS, overall survival; CSS, cancer-specific survival; CI, confidence interval; HR, hazard ratio.

Prognostic factors of RCC patients without ACS. It is well known that patients with RCC and accompanying ACS have a poor prognosis $(14,15)$. In the present study, the mean BMI of patients with ACS $\left(21.5 \mathrm{~kg} / \mathrm{m}^{2}\right)$ was significantly lower than that of patients without ACS $\left(23.5 \mathrm{~kg} / \mathrm{m}^{2} ; \mathrm{P}<0.0001\right.$; Table II). OS was significantly shorter in patients with ACS than it was in those without ACS (log-rank, $\mathrm{P}<0.0001$; Fig. 1B). On univariate Cox proportional analysis, both low BMI and presence of ACS were associated with shorter OS $(\mathrm{P}=0.0044$ and $\mathrm{P}<0.0001$, respectively; Table III) and shorter CSS $(\mathrm{P}=0.0081$ and $\mathrm{P}<0.0001$, respectively; Table III). Also significantly associated with shorter OS and shorter CSS on univariate analysis were age $(\mathrm{P}=0.0002$ and $\mathrm{P}=0.0053$, respectively), ECOG-PS (both $\mathrm{P}<0.0001$ ), pathological T stage (both $\mathrm{P}<0.0001$ ), regional $\mathrm{LN}$ involvement (both $\mathrm{P}<0.0001$ ), distant metastasis (both $\mathrm{P}<0.0001$ ), higher tumor grade (both $\mathrm{P}<0.0001$ ), infiltration pattern (both $\mathrm{P}<0.0001$ ) and venous invasion (both $\mathrm{P}<0.0001$; Table III). On multivariate analysis, age $(\mathrm{P}=0.0193)$, the presence of ACS $(\mathrm{P}=0.0089)$, pathological $\mathrm{T}$ stage $(\mathrm{P}=0.0013)$, regional $\mathrm{LN}$ involvement $(\mathrm{P}=0.0129)$ and distant metastasis $(\mathrm{P}<0.0001)$ were independent predictors of shorter OS; however, BMI was not $(\mathrm{P}=0.5440)$. On multivariate analysis, the presence of $\mathrm{ACS}(\mathrm{P}=0.0308)$, pathological $\mathrm{T}$ stage $(\mathrm{P}=0.0011)$, regional $\mathrm{LN}$ involvement $(\mathrm{P}=0.0062)$ and distant metastasis $(\mathrm{P}<0.0001)$ were independent predictors of shorter CSS; however, BMI was not $(\mathrm{P}=0.6804)$. Furthermore, the impact of BMI on clinicopathological parameters in patients without ACS was also analyzed. Although in overall patients BMI was significantly lower in patients with aggressive forms of tumors (high grade, $\mathrm{P}=0.0027$; distant metastasis, $\mathrm{P}=0.0025$; infiltrative growth pattern, $\mathrm{P}=0.0453$; Table II), in patients without ACS there was no significant association between BMI and any pathological parameters (Table II). Additionally, BMI was not associated with OS in patients without ACS (log-rank, $\mathrm{P}=0.4591$; Fig. 1C).

Most important constituent factor of ACS associated with poor prognosis. We analyzed which constituent factor of ACS was more important for the prediction of poor OS and CSS. On univariate Cox proportional analysis, all factors were significantly associated with shorter OS (all P<0.0001; Table IV) and shorter CSS (all $\mathrm{P}<0.0001$; Table IV). On multivariate analysis, the presence of weight loss was the only significant predictor of shorter OS $[\mathrm{P}=0.0004$; hazard ratio (HR), 8.34;
95\% confidence interval (CI), 2.38-28.9] and shorter CSS ( $\mathrm{P}=0.0009 ; \mathrm{HR}, 8.26$; 95\% CI, 2.21-30.5).

\section{Discussion}

BMI has routinely been used as a convenient index of obesity in several studies, and it has been suggested that increased BMI is associated not only with increased risk of various malignant neoplasms, but also with poor survival $(2,3,6,7)$. Although obesity has been reported to increase the risk of RCC, a higher BMI is paradoxically associated with improved survival following nephrectomy (10-13). Some studies in the United States have demonstrated that patients who are overweight $\left(25 \leq \mathrm{BMI}<30 \mathrm{~kg} / \mathrm{m}^{2}\right)$ or obese $\left(\mathrm{BMI} \geq 30 \mathrm{~kg} / \mathrm{m}^{2}\right)$ are less likely to present features of aggressive tumors $(9,13)$. In addition, a study by Haferkamp et al (10) indicated that, in Europe, being underweight $\left(\mathrm{BMI}<18.5 \mathrm{~kg} / \mathrm{m}^{2}\right)$ at the time of nephrectomy worsened the prognosis of patients with RCC more than four-fold. This tendency is not limited to the Western world, but is also seen in Asian populations $(11,12)$. In accordance with previous studies, the present study demonstrated that a low BMI was significantly associated with increased tumor aggressiveness and poor survival. The relationship between low BMI and increased tumor aggressiveness and poor survival, however, was inconsistent with the relationship between obesity and increased risk of RCC, and the underlying mechanism remains unknown.

Low BMI in cancer patients could be explained by several mechanisms. One is decreased weight due to cancer-related ACS. Several studies have indicated ACS to be a strong predictor of poor prognosis in RCC $(14,15)$. ACS is one of the paraneoplastic symptoms frequently observed in patients with RCC and is caused by increased secretion of various cytokines and growth factors from cancer cells, among which are interleukin-6, vascular endothelial growth factor and platelet-derived growth factor (20-22). The present study demonstrated that there was also a significant association between low BMI and the presence of ACS, and that ACS was an independent predictor of poor OS and poor CSS; however, it also demonstrated that BMI was not an independent predictor of survival. In addition, in patients without ACS, no significant association was indicated between BMI and pathological parameters and clinical outcome. These results suggested that the impact of low BMI on aggressive clinicopathological 
parameters and poor clinical outcome in patients with RCC could be due to ACS. Haferkamp et al (10) conjectured that their finding of being underweight to be a poor predictor of RCC was partially due to cachexia. Their findings are consistent with the present results.

The field of obesity has moved beyond simple measurement of BMI, and the association of nutrition and body composition with prognosis in RCC is an area of contemporary interest (23). Although BMI is a simple and useful parameter of obesity, it does not necessarily reflect excessive adiposity because it is influenced by the amounts of both muscle and fat (23). The body fat distribution determined by measuring the visceral fat area (VFA) and the subcutaneous fat area by computed tomography (CT) has been used to assess adiposity not only in screening for cardiovascular events and metabolic syndrome, but also in monitoring clinical outcome in various types of cancer $(24,25)$. Visceral and subcutaneous fat have quite different properties in terms of metabolic activity, sensitivity to lipolysis and insulin-resistance (26). In particular, increased visceral fat deposition is strongly associated not only with increased risk of hyperglycemia, hyperinsulinemia and cardiovascular events, but also with increased risk of breast and colorectal cancer (26-28). The relationship between VFA and clinicopathological parameters and clinical outcome in RCC patients has also been investigated; however, the clinical significance of CT-estimated VFA in predicting clinicopathological parameters remains controversial (23). The mechanism of cancer-related ACS in patients with aggressive cancer is closely related both to body composition and nutrition. Research has demonstrated that ACS is characterized by preferential loss of adipose tissue and that in progressive ACS, body fat is lost more rapidly than lean tissue $(29,30)$. The clinical value of fat distribution pattern in predicting RCC progression may be improved by combining the pattern with the result of ACS assessment, which should be elucidated in future research.

The present study had some limitations that must be acknowledged. Firstly, the definition of ACS may include the impact of factors such as poor psychological health, low physical activity and low socioeconomic status (31). The present study used hypoalbuminemia as an index of the malnutrition in ACS; however, in the evaluation of malnutrition there are individual differences depending on age, sex and previous medical history. Secondly, the Asian body composition profile differs from that of other races (19), and the present study used a population comprised only of Japanese patients. Therefore, the BMI of patients in the present study may have been different from that of patients in most Western countries, and we would suggest that this underlying influence, that is cancer-related ACS, applies only to Asian populations. Thirdly, the patient selection was biased as the present study was a retrospective and single-hospital study.

Despite these limitations, in conclusion, the results of the present study demonstrated that BMI is not associated with tumor aggressiveness and prognosis of RCC when patients with ACS are excluded, and that the previously reported association between low BMI and poor prognosis of RCC could be due to ACS. These results should be validated in a prospective multi-institutional study conducted in Asian nations.

\section{References}

1. Ng M, Fleming T, Robinson M, Thomson B, Graetz N, Margono C, Mullany EC, Biryukov S, Abbafati C, Abera SF, et al: Global, regional, and national prevalence of overweight and obesity in children and adults during 1980-2013: A systematic analysis for the global burden of disease study 2013. Lancet 384: 766-781, 2014.

2. Friedman JM: Obesity: Causes and control of excess body fat. Nature 459: 340-342, 2009.

3. Renehan AG, Tyson M, Egger M, Heller RF and Zwahlen M: Body-mass index and incidence of cancer: A systematic review and meta-analysis of prospective observational studies. Lancet 371: 569-578, 2008.

4. Bjorge T, Tretli S and Engeland A: Relation of height and body mass index to renal cell carcinoma in two million Norwegian men and women. Am J Epidemiol 160: 1168-1176, 2004.

5. Pischon T, Lahmann PH, Boeing H, Tjønneland A, Halkjaer J, Overvad K, Klipstein-Grobusch K, Linseisen J, Becker N, Trichopoulou A, et al: Body size and risk of renal cell carcinoma in the European prospective investigation into cancer and nutrition (EPIC). Int J Cancer 118: 728-738, 2006.

6. Bardou M, Barkun AN and Martel M: Obesity and colorectal cancer. Gut 62: 933-947, 2013.

7. Cantarutti A, Bonn SE, Adami HO, Grönberg H, Bellocco R and Bälter K: Body mass index and mortality in men with prostate cancer. Prostate 75: 1129-1136, 2015.

8. Schips L, Lipsky K, Zigeuner R, Gidaro S, Salfellner M, Rehak P, Pummer K and Hubmer G: Does overweight impact on the prognosis of patients with renal cell carcinoma? A single center experience of 683 patients. J Surg Oncol 88: 57-62, 2014.

9. Parker AS, Lohse CM, Cheville JC, Thiel DD, Leibovich BC and Blute ML: Greater body mass index is associated with better pathologic features and improved outcome among patients treated surgically for clear cell renal cell carcinoma. Urology 68: 741-746, 2006.

10. Haferkamp A, Pritsch M, Bedke J, Wagener N, Pfitzenmaier J, Buse $\mathrm{S}$ and Hohenfellner M: The influence of body mass index on the long-term survival of patients with renal cell carcinoma after tumour nephrectomy. BJU Int 101: 1243-1246, 2008.

11. Awakura Y, Nakamura E, Ito N, Yamasaki T, Kamba T, Kamoto T and Ogawa O: Influence of body mass index on prognosis of Japanese patients with renal cell carcinoma. Urology 70: 50-54, 2007.

12. Choi Y, Park B, Jeong BC, Seo SI, Jeon SS, Choi HY, Adami HO, Lee JE and Lee HM: Body mass index and survival in patients with renal cell carcinoma: A clinical-based cohort and meta-analysis. Int J Cancer 132: 625-634, 2013.

13. Hakimi AA, Furberg H, Zabor EC, Jacobsen A, Schultz N, Ciriello G, Mikklineni N, Fiegoli B, Kim PH, Voss MH, et al: An epidemiologic and genomic investigation into the obesity paradox in renal cell carcinoma. J Natl Cancer Inst 105: 1862-1870, 2013.

14. Kim HL, Belldegrun AS, Freitas DG, Bui MH, Han KR, Dorey FJ and Figlin RA: Paraneoplastic signs and symptoms of renal cell carcinoma: Implications for prognosis. J Urol 170: 1742-1746, 2003.

15. Kim HL, Han KR, Zisman A, Figlin RA and Belldegrun AS: Cachexia-like symptoms predict a worse prognosis in localized t1 renal cell carcinoma. J Urol 171: 1810-1813, 2004.

16. Wolf I, Sadetzki S, Kanety H, Kundel Y, Pariente C, Epstein N, Oberman B, Catane R, Kaufman B and Shimon I: Adiponectin, ghrelin, and leptin in cancer cachexia in breast and colon cancer patients. Cancer 106: 966-973, 2006.

17. Edge SB and Compton CC: The American joint committee on cancer: The 7th edition of the AJCC cancer staging manual and the future of TNM. Ann Surg Oncol 17: 1471-1474, 2010.

18. Oken MM, Creech RH, Tormey DC, Horton J, Davis TE, McFadden ET and Carbone PP: Toxicity and response criteria of the eastern cooperative oncology group. Am J Clin Oncol 5: 649-655, 1982.

19. WHO Expert Consultation: Appropriate body-mass index for Asian populations and its implications for policy and intervention strategies. Lancet 363: 157-163, 2004.

20. Horiguchi A, Oya M, Marumo K and Murai M: STAT3, but not ERKs, mediates the IL-6-induced proliferation of renal cancer cells, ACHN and 769P. Kidney Int 61: 926-938, 2002.

21. Ding GX, Feng CC, Song NH, Fang ZJ, Xia GW, Jiang HW, Hua LX and Ding Q: Paraneoplastic symptoms: Cachexia, polycythemia, and hypercalcemia are, respectively, related to vascular endothelial growth factor (VEGF) expression in renal clear cell carcinoma. Urol Oncol 31: 1820-1825, 2013. 
22. Oya M: Renal cell carcinoma: Biological features and rationale for molecular-targeted therapy. Keio J Med 58: 1-11, 2009.

23. Park YH, Lee JK, Kim KM, Kook HR, Lee H, Kim KB, Lee S, Byun SS and Lee SE: Visceral obesity in predicting oncologic outcomes of localized renal cell carcinoma. J Urol 192 1043-1049, 2014.

24. Fox CS, Massaro JM, Hoffmann U, Pou KM, Maurovich-Horvat P, Liu CY, Vasan RS, Murabito JM, Meigs JB, Cupples LA, et al: Abdominal visceral and subcutaneous adipose tissue compartments: Association with metabolic risk factors in the framingham heart study. Circulation 116: 39-48, 2007.

25. Doyle SL, Donohoe CL, Lysaght J and Reynolds JV: Visceral obesity, metabolic syndrome, insulin resistance and cancer. Proc Nutr Soc 71: 181-189, 2012

26. Ibrahim MM: Subcutaneous and visceral adipose tissue: Structural and functional differences. Obes Rev 11: 11-18, 2010.

27. Schapira DV, Clark RA, Wolff PA, Jarrett AR, Kumar NB and Aziz NM: Visceral obesity and breast cancer risk. Cancer 74 632-639, 1994.

28. Oh TH, Byeon JS, Myung SJ, Yang SK, Choi KS, Chung JW, Kim B, Lee D, Byun JH, Jang SJ and Kim JH: Visceral obesity as a risk factor for colorectal neoplasm. J Gastroenterol Hepatol 23: 411-417, 2008
29. Dahlman I, Mejhert N, Linder K, Agustsson T, Mutch DM, Kulyte A, Isaksson B, Permert J, Petrovic N, Nedergaard J, et al: Adipose tissue pathways involved in weight loss of cancer cachexia. Br J Cancer 102: 1541-1548, 2010.

30. Fouladiun M, Körner U, Bosaeus I, Daneryd P, Hyltander A and Lundholm KG: Body composition and time course changes in regional distribution of fat and lean tissue in unselected cancer patients on palliative care-correlations with food intake, metabolism, exercise capacity, and hormones. Cancer 103: 2189-2198, 2005.

31. Ali SM and Lindström M: Socioeconomic, psychosocial, behavioural, and psychological determinants of BMI among young women: Differing patterns for underweight and overweight/obesity. Eur J Public Health 16: 325-331, 2006.

This work is licensed under a Creative Commons Attribution-NonCommercial-NoDerivatives 4.0 International (CC BY-NC-ND 4.0) License. 